\title{
Apolipoprotein $\varepsilon 4$ polymorphism does not modify the association between body mass index and high-density lipoprotein cholesterol: a cross-sectional cohort study
}

\author{
Catherine R Rahilly-Tierney ${ }^{1,3,4^{*}}$, Donna K Arnett ${ }^{5}$, Kari E North ${ }^{6}$, James S Pankow ${ }^{7}$, Steven C Hunt ${ }^{8}$, R Curtis Ellison ${ }^{9}$ \\ , J Michael Gaziano ${ }^{1,2,3,4}$ and Luc Djoussé $e^{1,2,3,4}$
}

\begin{abstract}
Background: We sought to examine whether $\varepsilon 4$ carrier status modifies the relation between body mass index (BMI) and HDL. The National Heart, Lung, and Blood Institute Family Heart Study included 657 families with high family risk scores for coronary heart disease and 588 randomly selected families of probands in the Framingham, Atherosclerosis Risk in Communities, and Utah Family Health Tree studies. We selected 1402 subjects who had $\varepsilon 4$ carrier status available. We used generalized estimating equations to examine the interaction between $\mathrm{BMI}$ and $\varepsilon 4$ allele carrier status on HDL after adjusting for age, gender, smoking, alcohol intake, mono- and poly-unsaturated fat intake, exercise, comorbidities, LDL, and family cluster.
\end{abstract}

Results: The mean (standard deviation) age of included subjects was 56.4(11.0) years and 47\% were male. Adjusted means of HDL for normal, overweight, and obese BMl categories were 51.2( \pm 0.97$), 45.0( \pm 0.75)$, and $41.6( \pm 0.93)$, respectively, among $397 \varepsilon 4$ carriers ( $p$ for trend < 0.0001) and 53.6( \pm 0.62$), 51.3( \pm 0.49)$, and $45.0( \pm 0.62)$, respectively, among 1005 non-carriers of the $\varepsilon 4$ allele ( $p$-value for trend $<0.0001)$. There was no evidence for an interaction between $\mathrm{BMI}$ and $\varepsilon 4$ status on $\mathrm{HDL}(\mathrm{p}$-value 0.39 ).

Conclusion: Our findings do not support an interaction between $\varepsilon 4$ allele status and BMI on HDL.

Keywords: HDL cholesterol, body mass index, genetic epidemiology, apolipoproteins, lipid metabolism, adiposity

\section{Introduction}

HDL cholesterol (HDL) has been associated with lower risk of coronary heart disease (CHD) in observational and trial cohorts [1-8]. Apolipoprotein E (APOE) is a protein component of triglyceride-rich lipoproteins and thus participates in the transport of lipids among various cells in the body [9]. There are 3 major isoforms of apolipoprotein $\mathrm{E}$ in modern populations, encoded by alleles $\varepsilon 2$, $\varepsilon 3$, and $\varepsilon 4$. The $\varepsilon 4$ allele has been associated with lower levels of HDL and higher risk of CHD events [10]. Higher body mass index (BMI) has also been found to be associated with lower HDL levels and increased risk of

\footnotetext{
* Correspondence: crahilly-tierney@partners.org

'Massachusetts Veterans Epidemiology and Information Research Center (MAVERIC), Boston VA Healthcare, Boston, Massachusetts, USA

Full list of author information is available at the end of the article
}

CHD [11-13]. In studies including subjects at average risk for CHD, previous researchers have not found that a BMI-genotype interaction impacts HDL levels [14-16]. However, to the best of our knowledge, no researchers have reported whether APOE $\varepsilon 4$ allele carrier status modifies the relation between higher BMI and lower HDL levels in a cohort enriched with subjects and higher-than-average risk for CHD. This question may be important from a clinical standpoint, to determine whether carriers of Apo $\varepsilon 4$ are at any disadvantage when attempting to lower their BMI to achieve a more favorable lipid profile. Therefore, to evaluate whether there is a significant interaction between BMI and APOE $\varepsilon 4$ carrier status on HDL levels, we examined the relationship between these in a cohort of 1402 men and women

\section{C) Biomed Central}


selected from the National Heart, Lung, and Blood Institute Family Heart Study (NHLBI FHS).

\section{Methods \\ Population}

The NHLBI FHS is a multicenter, population-based study that includes probands recruited from three parent studies: the Framingham Heart Study (Framingham, MA), the Atherosclerosis Risk in Communities Study (Forsythe County, NC and Minneapolis, MN), and the Utah Family Health Tree (Salt Lake City, UT). Between 1993 and 1995, 2,000 randomly selected participants and 2,000 with family histories of CHD enrolled in the 3 parent studies were mailed invitations to provide information regarding the health of themselves, their parents, their children, and their siblings. Of these, 3,150 returned responses, and family members of these responders were contacted. From the 22,908 persons who provided information, 588 families were randomly selected and an additional 657 with high family risk scores were also selected. Family risk score was calculated by comparing the actual incidence of CHD to the age- and sex-adjusted expected incidence of $\mathrm{CHD}$ within a family. Enrollees underwent study examinations during which height, weight and blood pressure were documented, and 12-hour fasting blood samples were taken on which lipids and other parameters were measured, and from which DNA was stored. Genotyping for the APOE allele was performed on a selection of FHS participants. More detailed description of the methods of the NHLBI FHS have been described previously [17]. The FHS is supported by the National Heart, Lung, and Blood Institute (NHLBI) (grant numbers U01 HL56563, U01 HL56564, U01 HL56565, U01 HL56566, U01 HL56567, U01 HL56568, U01 HL56569, and K01-HL70444). Each participant in the FHS gave informed consent and the study protocol was reviewed and approved by the respective Internal Review Boards at each of the participating institutions.

For this study, we selected subjects with information on APOE genotype and with complete data on lipids, lifestyle factors, and co-morbidities. Due to small numbers of non-white subjects, participants of other races ( 54 subjects) were excluded from this study, as were 34 subjects who were using cholesterol modifying therapy. Finally 37 subjects were excluded with the $\varepsilon 2 / \varepsilon 4$ genotype, as the $\varepsilon 2$ allele has been associated with higher levels of HDL while $\varepsilon 4$ carrier status has been associated with lower HDL levels [18].

\section{Exposure}

APOE genotyping was performed using polymerase chain reaction (PCR) to amplify a 267-base pair fragment from exon 3 of the APOE gene. The PCR product was digested using the Hha-1 restriction endonuclease, which resulted in a specific banding pattern for the 3 isoforms of the apolipoprotein $\mathrm{E}$ protein when separated by polyacrylamide gel electrophoresis and silver stained [19]. Subjects with genotypes of $\varepsilon 3 / \varepsilon 4$ or $\varepsilon 4 / \varepsilon 4$ were carriers; subjects with genotypes of $\varepsilon 2 / \varepsilon 2, \varepsilon 2 / \varepsilon 3$, or $\varepsilon 3 / \varepsilon 3$ were non-carriers.

Height and weight documented during the study examination were used to calculate body mass index (BMI). BMI was treated both as a continuous and a categorized variable (BMI $<25 \mathrm{~kg} / \mathrm{m}^{2}, 25 \leq \mathrm{BMI}<30 \mathrm{~kg} / \mathrm{m}^{2}$, and BMI $\left.\geq 30 \mathrm{~kg} / \mathrm{m}^{2}\right)$ in the analyses described below.

\section{Lipid measurements}

During the study visits, a fasting blood sample was collected in evacuated tubes without additives, spun at $3000 \mathrm{xg}$ for 10 minutes at $4{ }^{\circ} \mathrm{C}$, and stored at $-70^{\circ}$ until they were processed. HDL, total cholesterol, and triglyceride concentrations were measured using a COBAS FARA high-speed centrifugal analyzer (Roche Diagnostic Systems, Montclair, New Jersey).

\section{Covariates}

Information on lifestyle factors including smoking (currently smoking versus not currently smoking), alcohol intake (consumption of 2 or more beverages daily), and physical activity (minutes of exercise per day) was obtained by interview during the study visit. Mono- and poly-unsaturated fat intake (MUFA and PUFA, in grams) was determined using a previously validated food frequency questionnaire administered by study staff during the study interview and a nutrient database from Harvard University supplemented by manufacturer's information [20]. Participants provided self-reported information on co-morbities including angina, CHD, stroke, cancers, and hypertension. A subject was deemed to have diabetes mellitus if he was taking hypoglycemic agents, if a physician had told the subject that he had diabetes mellitus, or if fasting blood glucose was $\geq 126 \mathrm{mg} / \mathrm{dL}$. In subjects with triglycerides $<400 \mathrm{mg} / \mathrm{dL}$, LDL (LDL) was calculated using measured HDL, total cholesterol, and triglycerides. LDL was measured directly on EDTA plasma using ultracentrifugation on EDTA plasma in subjects with triglycerides $\geq 400 \mathrm{mg} / \mathrm{dL}$.

\section{Statistical Analyses}

The chi-square test was used to determine whether the APOE allele distribution was in Hardy-Weinberg equilibrium in this population prior to exclusions. We compared characteristics of the cohort by $\varepsilon 4$ carrier status and by BMI category, using t-tests to compare continuous variables and Cochran-Mantel-Haenszel tests to compare categorical variables. We then used generalized estimating equations (GEE, using the LSMEANS option in PROC GENMOD in SAS) to determine adjusted means and 
standard errors for HDL across BMI categories, in subgroups by $\varepsilon 4$ carrier status. GEE adjusts for familial clustering in the NHLBI FHS. Means were adjusted for age, categorized BMI, gender, current smoking status, alcohol consumption ( $\geq 2$ beverages daily versus non or $<$ 2 daily), minutes of exercise daily, mono- and PUFA intake in grams, angina, stroke, hypertension, coronary heart disease, diabetes mellitus, and LDL. We determined the parameter estimate and p-value for a categorized BMIxe4 carrier product term in a model including the main effects of categorized BMI and carrier status, plus age, gender, lifestyle factors, co-morbidities, and LDL. In secondary analyses, we examined whether a continuous BMIx\&4 carrier product term was significantly associated with HDL after adjusting for the main effects of continuous BMI and carrier status and age, then additionally adjusting for gender, lifestyle factors, co-morbidities, and LDL. We did not include triglycerides in adjusted models due to collinearity between the outcome (HDL) and triglycerides as previously modeled by others [21].

In a sensitivity analysis, we examined whether there was a significant association between continuous BMIx\&4 carrier product term and HDL in a sub-cohort consisting of one individual (randomly selected) per family, and in subgroups of participants defined by CHD risk (members of randomly selected families versus members of families with increased CHD risk). To examine whether there was a significant interaction between BMI and APOE genotype (in contrast to carrier status for the $\varepsilon 4$ allele) we treated genotype as an ordinal variable $(\varepsilon 2 / \varepsilon 2, \varepsilon 2 / \varepsilon 3, \varepsilon 3 /$ $\varepsilon 3, \varepsilon 3 / \varepsilon 4, \varepsilon 4 / \varepsilon 4)$ and included a continuous BMIxgenotype product term in the model. To examine whether a BMIxe4 carrier status interaction was significantly associated with HDL in subgroups by gender, we repeated the analysis including the main effects of BMI and $\varepsilon 4$ carrier status and their interaction term in subgroups of men and women. All analyses were performed using SAS version 9.2 (SAS Institute Incorporated, Cary, North Carolina).

\section{Results}

A total of 1402 NHLBI FHS participants from 662 families were included in our study. Each family contributed an average of 2 participants to our cohort (range, 111 family members). The mean (standard deviation, SD) age of the study cohort was 56.4 (11.0) years, $47 \%$ were male, and about $75 \%$ had a BMI within the overweight or obese range $\left(\geq 25 \mathrm{~kg} / \mathrm{m}^{2}\right)$. As expected given the selection method for the study, there was a high prevalence of smoking (13\%), angina (14\%), CHD (18\%), and hypertension (34\%). The distribution of the APOE alleles was in Hardy-Weinberg equilibrium ( $p$-value 0.91). Overall, 28\% of subjects were carriers of the APOE $\varepsilon 4$ allele. Table 1 presents characteristics of the cohort by $\varepsilon 4$ carrier status. The mean HDL among $\varepsilon 4$ carriers was significantly lower and the mean triglycerides significantly higher than those among non-carriers. Carriers of the $\varepsilon 4$ allele were younger and more likely than non-carriers to be hypertensive. Table 2 presents characteristics of the cohort according to BMI category. Subjects with higher BMI

Table 1 Characteristics of $n=1402$ National Heart, Lung, and Blood, Institute Family Heart Study participants, by apolipoprotein $\& 4$ carrier status.

\begin{tabular}{|c|c|c|c|}
\hline Characteristic & $\begin{array}{c}\text { Carriers of } \varepsilon 4 \\
\mathrm{n}=397(28.3 \%)\end{array}$ & $\begin{array}{c}\text { Non-carriers of } \varepsilon 4 \\
\mathrm{n}=1005(71.7 \%)\end{array}$ & p-value \\
\hline Age, mean $(S D)^{*}$ & $54.9(10.9)$ & $57.0(11.0)$ & 0.001 \\
\hline Male, no. $(\%)^{*}$ & 193(48.6) & $472(47.0)$ & 0.58 \\
\hline $\mathrm{BMI}, \mathrm{kg} / \mathrm{m}^{2}$, mean $(\mathrm{SD})^{*}$ & 28.3(5.3) & 28.4(5.6) & 0.89 \\
\hline Current smoker, no. (\%) & $45(11.3)$ & 138(13.7) & 0.23 \\
\hline$\geq 2$ alcoholic drinks daily, no. (\%) & 197(49.6) & $497(49.5)$ & 0.95 \\
\hline Monounsaturated fat intake, g/day, mean (SD) & 24.7(13.9) & $23.3(12.5)$ & 0.06 \\
\hline Polyunsaturated fat intake, g/day, mean (SD) & $9.1(5.1)$ & $8.7(4.6)$ & 0.17 \\
\hline Exercise in minutes/day, mean (SD) & $26.8(37.3)$ & 28.2(34.7) & 0.51 \\
\hline $\mathrm{HDL}, \mathrm{mg} / \mathrm{dL}$, mean $(\mathrm{SD})^{*}$ & $45.8(14.1)$ & 49.1(15.8) & 0.0003 \\
\hline LDL, mg/dL, mean (SD) & 132.8(37.0) & $128.8(35.5)$ & 0.06 \\
\hline Triglycerides, mg/dL, mean (SD) & $178.7(102.0)$ & 164.4(109.3) & 0.03 \\
\hline Diabetes mellitus, no. (\%) & $27(6.8)$ & $95(9.5)$ & 0.11 \\
\hline Hypertension, no. (\%) & $116(29.2)$ & $364(36.2)$ & 0.01 \\
\hline Coronary heart disease, no. (\%) & $72(18.1)$ & $176(17.5)$ & 0.78 \\
\hline Angina, no. (\%) & $46(11.6)$ & 150(14.9) & 0.10 \\
\hline Stroke, no. (\%) & 13(3.3) & $35(3.5)$ & 0.85 \\
\hline Cancer, no. (\%) & $45(11.3)$ & 111(11.0) & 0.88 \\
\hline
\end{tabular}

*BMI = Body Mass Index; $\mathrm{HDL}=$ high-density lipoprotein cholesterol; kg/m² = kilograms/meters-squared; $\mathrm{LDL}=$ low-density lipoprotein cholesterol; $\mathrm{mg} / \mathrm{dL}=$ milligrams/deciliter; No. = number; SD = standard deviation 
Table 2 Characteristics of the $n=1402$ participants, by category of body mass index.

\begin{tabular}{|c|c|c|c|c|}
\hline Characteristic & $\begin{array}{c}\mathrm{BMI} \leq 25 \mathrm{~kg} / \mathrm{m}^{2 *} \\
\mathrm{n}=407(29.0 \%)\end{array}$ & $\begin{array}{c}25<\mathrm{BMI} \leq 30 \mathrm{~kg} / \mathrm{m}^{2} \\
\mathrm{n}=565(40.3 \%)\end{array}$ & $\begin{array}{l}\text { BMI > } 30 \mathrm{~kg} / \mathrm{m}^{2} \\
\mathrm{n}=430(30.7 \%)\end{array}$ & p-value \\
\hline Age, mean $(S D)^{*}$ & $56.2(11.1)$ & $57.1(11.3)$ & $55.8(10.6)$ & 0.57 \\
\hline Carrier $\varepsilon 4$ allele, no. (\%)* & $112(27.5)$ & $162(28.7)$ & $123(28.6)$ & 0.73 \\
\hline Male, no. (\%) & $143(35.1)$ & $330(58.4)$ & $192(44.7)$ & 0.008 \\
\hline $\mathrm{BMl}, \mathrm{kg} / \mathrm{m}^{2}$, mean $(\mathrm{SD})^{*}$ & $22.8(1.7)$ & $27.4(1.4)$ & $34.9(4.6)$ & - \\
\hline Current smoker, no. (\%) & $69(17.0)$ & $77(13.6)$ & $37(8.6)$ & 0.0003 \\
\hline$\geq 2$ alcoholic drinks daily, no. (\%) & $209(51.4)$ & $287(50.8)$ & $198(46.1)$ & 0.12 \\
\hline Monounsaturated fat intake, mean (SD) & $21.8(12.6)$ & $24.0(12.5)$ & $25.0(37.0)$ & 0.0004 \\
\hline Polyunsaturated fat intake, mean (SD) & $8.4(4.4)$ & $8.9(4.7)$ & $9.2(5.1)$ & 0.02 \\
\hline Exercise in minutes/day, mean (SD) & $30.1(33.8)$ & $28.6(35.3)$ & $24.5(37.0)$ & 0.02 \\
\hline $\mathrm{HDL}, \mathrm{mg} / \mathrm{dL}$, mean $(\mathrm{SD})^{*}$ & $55.1(17.5)$ & $46.5(14.2)$ & $44.0(12.4)$ & $<0.0001$ \\
\hline $\mathrm{LDL}, \mathrm{mg} / \mathrm{dL}$, mean $(\mathrm{SD})^{*}$ & $129.7(35.1)$ & $131.5(38.9)$ & $128.2(32.5)$ & 0.53 \\
\hline Triglycerides, mg/dL, mean (SD) & $134.0(105.7)$ & $179.5(103.0)$ & $186.6(107.5)$ & $<0.0001$ \\
\hline Diabetes mellitus, no. (\%) & $17(4.2)$ & $53(9.4)$ & $52(12.1)$ & $<0.0001$ \\
\hline Hypertension, no. (\%) & $103(25.3)$ & $202(35.8)$ & $175(40.7)$ & $<0.0001$ \\
\hline Coronary heart disease, no. (\%) & $57(14.0)$ & $127(22.5)$ & $64(14.9)$ & 0.79 \\
\hline Angina, no. (\%) & $36(8.9)$ & $107(18.9)$ & $53(12.3)$ & 0.17 \\
\hline Stroke, no. (\%) & $9(2.2)$ & $28(5.0)$ & $11(2.6)$ & 0.82 \\
\hline Cancer, no. (\%) & $38(9.3)$ & $73(12.9)$ & $45(10.5)$ & 0.63 \\
\hline
\end{tabular}

${ }^{*} \mathrm{BMI}=$ Body Mass Index; HDL = high-density lipoprotein cholesterol; $\mathrm{kg} / \mathrm{m}^{2}=$ kilograms/meters-squared; LDL = low-density lipoprotein cholesterol; $\mathrm{mg} / \mathrm{dL}=$ milligrams/deciliter; No. = number; SD = standard deviation

were more likely to be male, have a higher fat intake, exercised for fewer minutes daily, had lower HDL, and were more likely to have diabetes mellitus or hypertension.

Table 3 presents multivariate adjusted means \pm standard errors of HDL in each BMI category, in subgroups by $\varepsilon 4$ carrier status. As BMI increases, HDL decreases in both $\varepsilon 4$ carriers and non-carriers (p-value for trend < 0.0001 in each subgroup). In an analysis including the main effects of categorized BMI and $\varepsilon 4$ carrier status, there was no significant association between a categorized BMIx\&4 carrier product term and HDL (p-value 0.75 , results not shown). Table 3 also presents the parameter estimates and $\mathrm{p}$-values for BMI as a continuous

Table 3 Adjusted mean ( \pm standard error, SE) high-density lipoprotein cholesterol in each category of body mass index(BMI), by $\varepsilon 4$ carrier status (top section) and parameter estimates \pm SE and p-values for continuous BMI and continuous BMI $\times \& 4$ carrier status (bottom section).

\begin{tabular}{|c|c|c|c|c|c|c|}
\hline & n & $\varepsilon 4$ Carriers & $\mathrm{n}$ & $\varepsilon 4$ Non-carriers & Overall cohort & \\
\hline $\mathrm{HDL}^{\mathrm{a}}, \mathrm{mg} / \mathrm{dL}$, mean $\pm \mathrm{SE}^{*}$ & & & & & Parameter estimate(SE) & $p$-value \\
\hline $\mathrm{BMl} \leq 25 \mathrm{~kg} / \mathrm{m}^{2 *}$ & 112 & $51.2 \pm 0.97$ & 295 & $53.6 \pm 0.62$ & & \\
\hline $25<\mathrm{BMl} \leq 30 \mathrm{~kg} / \mathrm{m}^{2}$ & 162 & $45.0 \pm 0.75$ & 403 & $51.3 \pm 0.49$ & & \\
\hline $\mathrm{BMI} \geq 30 \mathrm{~kg} / \mathrm{m}^{2}$ & 123 & $41.6 \pm 0.93$ & 307 & $45.0 \pm 0.62$ & & \\
\hline P-value for trend & & $<0.0001$ & & $<0.0001$ & & \\
\hline \multicolumn{7}{|l|}{ BMI } \\
\hline Adjusted for age and carrier status & & & & & $-0.69(0.07)$ & $<0.0001$ \\
\hline Adjusted for age, carrier status, and interaction & & & & & $-0.70(0.08)$ & $<0.0001$ \\
\hline Multivariate-adjusted $^{\mathrm{b}}$ & & & & & $-0.75(0.07)$ & $<0.0001$ \\
\hline \multicolumn{7}{|l|}{ Continuous BMI $\times$ carrier term } \\
\hline Adjusted for age, BMI, and carrier status & & & & & $0.02(0.14)$ & 0.90 \\
\hline Multivariate-adjusted $^{\mathrm{b}}$ & & & & & $0.10(0.12)$ & 0.39 \\
\hline
\end{tabular}

*BMI = Body Mass Index; $\mathrm{HDL}=$ high-density lipoprotein cholesterol; $\mathrm{mg} / \mathrm{dL}=$ milligrams $/$ deciliter; $\mathrm{kg} / \mathrm{m}^{2}=\mathrm{kilograms} / \mathrm{meters}-\mathrm{squared}$

${ }^{+}$Multivariate-adjusted estimates for HDL are adjusted for age, gender, categorized BMl, current smoker (yes/no), alcohol intake( $\geq 2$ beverages daily, yes/no), monounsaturated fat intake in grams, polyunsaturated fat intake in grams, minutes of exercise daily, angina, coronary heart disease, stroke, cancer, hypertension, diabetes mellitus, and low-density lipoprotein cholesterol

${ }^{\mathrm{b}}$ Multivariate-adjusted parameter estimates are adjusted for age, gender, continuous BMI, $\varepsilon 4$ carrier status, continuous BMlx 4 carrier interaction, current smoker (yes/no), alcohol intake ( $\geq 2$ beverages daily, yes/no), monounsaturated fat intake in grams, polyunsaturated fat intake in grams, minutes of exercise daily, angina, coronary heart disease, stroke, cancer, hypertension, diabetes mellitus, and LDL. 
variable and for a continuous $\mathrm{BMI} \times \varepsilon 4$ carrier product term. The association between continuous BMI and HDL remains robust, with or without adjustment for the BMI $\times \varepsilon 4$ carrier product term and other co-variates including gender, lifestyle factors, LDL, and co-morbidities. In ageand multivariate-adjusted parameter estimates, there was no significant association between the continuous BMI $\times$ $\varepsilon 4$ carrier product term and HDL (multivariate parameter estimate 0.11 , p-value 0.39 ).

In a sensitivity analysis including one member per family, results again revealed that after adjusting for the main effects of BMI and $\varepsilon 4$ carrier status, a continuous $\mathrm{BMI} \times$ carrier product term remained non-significant (results not shown). Repeating the analysis in subgroups consisting of participants from randomly selected families versus those with increased CHD risk, we found that results were similar (not shown). In an analysis treating APOE genotype as an ordinal variable and including a continuous BMI $\times$ genotype product term, the interaction between genotype and BMI remained non -significant (p-value for interaction 0.55; p-value for main effects of continuous BMI and APOE genotype were 0.0008 and 0.24 respectively, when interaction term included in the model, results not shown). In an analysis including the main effects of continuous BMI and $\varepsilon 4$ carrier status and a continuous BMI $\times$ carrier product term in subgroups of men and women, results were unchanged (results not shown).

\section{Discussion}

In a cohort of 1402 men and women, we found that APOE $\varepsilon 4$ carrier status did not modify the strong association between higher BMI and lower HDL levels. We found that increasing BMI was significantly associated with decreasing HDL, regardless of whether or not subjects were carriers of the $\varepsilon 4$ allele. These findings were robust in subgroups by gender and in a cohort in which only one member per family was included. In analyses examining whether there was interaction between APOE genotype and the BMI-HDL association, we again found a strong association between increasing BMI and decreasing HDL levels, regardless of genotype.

In subjects at average risk for $\mathrm{CHD}$, previous researchers have found that APOE genotype does not modify the association between measures of adiposity, including BMI and waist-to-hip ratio, and HDL levels. In a Canadian cohort including 1788 men and women of varying CHD risk, Lussier-Cacan et al found that the relationship between BMI and HDL did not vary significantly across APOE genotypes [14]. We similarly found no difference in the relation between BMI and HDL in $\varepsilon 4$ carriers compared to noncarriers. In a cohort of 759 young adults (aged 20 to 32 years) followed longitudinally, obese individuals had much higher prevalence of low HDL levels compared to non- obese individuals, but this did not differ across APOE genotype categories [15]. Our study demonstrates that the lack of modification of the BMI-HDL relation by $\varepsilon 4$ carrier status also extends to populations enriched with subjects at higher risk for $\mathrm{CHD}$.

APOE is synthesized by the liver as part of VLDL particles. In cholesterol transport, it serves as a ligand for several processes that cycle triglycerides from VLDL into HDL subtypes. The $\varepsilon 4$ isoform of APOE is less effective in binding to lipoprotein receptors than the $\varepsilon 2$ or $\varepsilon 3$ isoforms, so in individuals with APOE $\varepsilon 4$ the pathway between triglyceride-rich VLDL particles and small, denser, more easily metabolized HDL particles is less effective [9]. Though further research would be necessary to support any speculation regarding the metabolic pathway between BMI, APOE, and HDL, our findings may suggest that in the triglyceride-rich milieu associated with adiposity, the effectiveness of the APOE as a ligand becomes immaterial as the pathway between VLDL and HDL subtypes is overwhelmed. In a supplemental analysis, we examined whether an interaction between BMI and APOE genotype impacted HDL levels and found no significant association. This lends further support to the idea that the effectiveness of one player, APOE, in the complex pathway that metabolizes lipids becomes less important in the context of high levels of substrate entering that pathway, as is the case in subjects with high BMI.

There are several advantages to using the NHLBI FHS database to examine whether there is a significant interaction between BMI and 84 carrier status in influencing HDL levels, including detailed information on several lifestyle factors that are associated with HDL (alcohol intake, smoking, diet, and exercise). Misclassification of the main exposure variable, namely BMI, is unlikely as height and weight were determined by study staff during the study visit. However there are some limitations to our study. The small number of non-Caucasian subjects disallowed us from examining whether there is a significant BMIxgenotype association with HDL in persons of other racial or ethnic groups. We may have been under-powered to detect a small effect of a BMI $\times$ APOE interaction on HDL levels. Confirming that no significant interaction exists in larger cohorts remains an important area of future research.

We found that $\varepsilon 4$ carrier status does not modify the well-established association between increasing BMI and decreasing HDL levels. Our findings suggest that carriers of the $\varepsilon 4$ allele who lower their BMI in an attempt to improve their lipid profile may not be at a disadvantage when compared to non-carriers of the allele. However, further study in larger cohorts and with subjects of other races or ethnicity are warranted to definitively establish whether $\varepsilon 4$ carrier status modifies the BMIHDL association. 


\section{List of Abbreviations}

APOE: apolipoprotein E; BMI: body mass index; Cl: confidence interval; $\mathrm{CHD}$ : coronary heart disease; GEE: generalized estimating equations; HR: hazard ratio; HDL: high density lipoprotein cholesterol; LDL: low density lipoprotein cholesterol; MUFA: mono-unsaturated fatty acid; NHLBI FHS: National Heart Lung \& Blood Institute Family Heart Study; PUFA: poly-unsaturated fatty acids; SD: standard deviation; VLDL: very low density lipoprotein cholesterol

\section{Acknowledgements}

The FHS is supported by the National Heart, Lung, and Blood Institute (NHLBI) (grant numbers U01 HL56563, U01 HL56564, U01 HL56565, U01 HL56566, U01 HL56567, U01 HL56568, U01 HL56569, and K01-HL70444). The funding body had no role in the collection, analysis, and interpretation of the data; in the writing of the manuscript; or in the decision to submit the manuscript for publication.

\section{Author details}

${ }^{1}$ Massachusetts Veterans Epidemiology and Information Research Center (MAVERIC), Boston VA Healthcare, Boston, Massachusetts, USA. ${ }^{2}$ Geriatric Research Education and Clinical Centers (GRECC), Boston VA Healthcare, Boston, Massachusetts, USA. ${ }^{3}$ Division of Aging, Brigham \& Women's Hospital, Boston, Massachusetts, USA. ${ }^{4}$ Harvard Medical School, Boston, Massachusetts, USA. ${ }^{5}$ Department of Epidemiology, University of Alabama at Birmingham School of Public Health, Birmingham, Alabama, USA. ${ }^{6}$ Carolina Center for Genome Science, University of North Carolina Gillings School of Global Public Heatlh, Chapel Hill, North Carolina, USA. ${ }^{7}$ Division of Epidemiology \& Community Health, University of Minnesota School of Public Health, Minneapolis, Minnesota, USA. ${ }^{8}$ Cardiovascular Genetics Division, University of Utah, Salt Lake City, Utah, USA. ${ }^{9}$ Section of Preventive Medicine \& Epidemiology, Boston University School of Medicine, Boston, Massachusetts, USA.

\section{Authors' contributions}

CRT and LD planned the study and designed the analysis. LD acquired the data. CRT executed the statistical analysis and prepared the tables. LD and CRT interpreted the results, and CRT drafted the manuscript. DKA, KEN, JSP, $S \mathrm{CH}$, and JMG were instrumental in editing the manuscript to its present form. All authors have read and approve the final manuscript.

\section{Competing interests}

The authors declare that they have no competing interests.

Received: 2 August 2011 Accepted: 23 September 2011

Published: 23 September 2011

\section{References}

1. Gordon T, Castelli WP, Hjortland MC, Kannel WB, Dawber TR: High density lipoprotein as a protective factor against coronary heart disease. The Framingham Study. Am J Med 1977, 62:707-714.

2. Gordon DJ, Probstfield JL, Garrison RJ, Neaton JD, Castelli WP, Knoke JD, Jacobs DR, Bandiwala S, Tyroler HA: HDL cholesterol and cardiovascular disease. Four prospective American studies. Circulation 1989, 79:8-15.

3. Miller NE, Thelle DS, Forde OH, Mjos OD: The Tromsø heart-study: HDL and coronary heart-disease: a prospective case-control study. Lancet 1977, 1:965-968

4. Perova NV, Organov RG, Williams DH, Irving SH, Abernathy JR, Deev AD, Shestov DB, Zhukovsky GS, Davis CE, Tyroler HA: Association of highdensity-lipoprotein cholesterol with mortality and other risk factors for major chronic noncommunicable disease in samples of US and Russian men. Ann Epidemiol 1995, 5:179-185.

5. Jacobs DR, Mebane IL, Bangdiwala SI, Criqui MH, Tyroler HA: High density lipoprotein cholesterol as a predictor of cardiovascular disease mortality in men and women: the follow-up study of the Lipid Research Clinics Prevalence Study. Am J Epidemiol 1990, 131:32-47.

6. Gordon DJ, Knoke J, Probstfield JL, Superko R, Tyroler HA: HDL cholesterol and coronary heart disease in hypercholesterolemic men: the Lipid Research Clinics Coronary Primary Prevention Trial. Circulation 1986, 74:1217-1225.

7. Svensvold I, Urdal P, Thürmer H, Tverdal A, Lund-Larsen PG, Foss OP: HDL cholesterol and coronary, cardiovascular, and all cause mortality among middle-aged Norwegian men and women. Eur Heart J 1992, 13:1155-1163.
8. Enger SC, Hjermann I, Foss OP, Helgeland A, Holme I, Leren P, Norum KR: High density lipoprotein cholesterol and myocardial infarction or sudden coronary death: a prospective case-control study in middle-aged men of the Oslo study. Artery 1979, 5:170-181.

9. Mahley RW, Rall SC Jr: Apolipoprotein E: far more than a lipid transport protein. Annu Rev Genomics Hum Genet 2000, 1:506-537.

10. Wilson PW, Myers RH, Larson MG, Ordovas JM, Wolf PA, Schaefer EJ: Apolipoprotein E alleles, dyslipidemia, and coronary heart disease. The Framingham Offspring Study. JAMA 1994, 272:1666-1671.

11. Weisweiler P: Plasma lipoproteins and lipase and lecithin: cholesterol acyltransferase activities in obese subjects before and after weight reduction. J Clin Endocrinol Metab 1987, 65:969-973.

12. Dattilo AM, Kris-Etherton PM: Effects of weight reduction on blood lipids and lipoproteins: a meta-analysis. Am J Clin Nutr 1992, 56:320-328.

13. Bowman TS, Kurth T, Sesso HD, Manson JE, Gaziano JM: Eight-year change in body mass index and subsequent risk of cardiovascular disease among healthy non-smoking men. Prev Med 2007, 45:436-441.

14. Lussier-Cacan S, Bolduc A, Xhignesse M, Niynsenga T, Connelly PW, Sing CF: Impact of age and body size on inter-individual variation in measures of lipid metabolism: influence of gender and apolipoprotein E genotype. Clin Genet 2000, 57:35-47.

15. Srinivasan SR, Ehnholm C, Elkasabany A, Berenson GS: Apolipoprotein E polymorphism modulates the association between obesity and dyslipidemias during young adulthood: the Bogalusa Heart Study. Metabolism 2001, 50:696-702.

16. Kee F, Young IS, Poirier O, McMaster D, McCrum E, McGeough J, Patterson CC, Dallongeville J, Cambien F, Evans AE: Do polymorphisms of apoB, LPL or apoE affect the hypocholesterolemic response to weight loss? Atherosclerosis 2000, 153:119-128.

17. Higgins M, Province M, Heiss G, Eckfeldt J, Ellison RC, Folsom AR, Rao DC, Sprafka JM, Williams R: NHLBI Family Heart Study: objectives and design. Am J Epidemiol 1996, 143:1219-1228.

18. Corbo RM, Scacchi R: Apolipoproten E (APOE) allele distribution in the world. Is APOE*4 a "thrifty" allele? Ann Hum Genet 1999, 63:301-310.

19. Reymer PW, Groenemeyer BE, van de Burg R, Kastelein JJ: Apolipoprotein E genotyping on agarose gels. Clin Chem 1995, 41:1046-1047.

20. Willett WC, Sampson L, Stampfer MJ, Rosner B, Bain C, Witschi J, Hennekens CH, Speizer FE: Reproducibility and validity of a semiquantitative food frequency questionnaire. Am J Epidemiol 1985, 122:51-65.

21. Criqui MH: Triglycerides and coronary heart disease revisited (again). Ann Intern Med 2007, 147:425-427.

doi:10.1186/1476-511X-10-167

Cite this article as: Rahilly-Tierney et al:: Apolipoprotein $\varepsilon 4$

polymorphism does not modify the association between body mass index and high-density lipoprotein cholesterol: a cross-sectional cohort study. Lipids in Health and Disease 2011 10:167.

\section{Submit your next manuscript to BioMed Central and take full advantage of:}

- Convenient online submission

- Thorough peer review

- No space constraints or color figure charges

- Immediate publication on acceptance

- Inclusion in PubMed, CAS, Scopus and Google Scholar

- Research which is freely available for redistribution

Submit your manuscript at www.biomedcentral.com/submit
Ciomed Central 